\title{
License to Sin: The Liberating Role of Reporting Expectations
}

\author{
GAVAN J. FITZSIMONS \\ JOSEPH C. NUNES \\ PATTI WILLIAMS*
}

\begin{abstract}
This research examines the impact of asking intention questions about "vice behaviors," or behaviors about which respondents simultaneously hold both negative explicit and positive implicit attitudes. Asking questions about the likelihood of engaging in behaviors for which respondents maintain conflicting attitude structures appears to give respondents a "license to sin," resulting in increased rates of behavior versus those of a control group not asked intention questions. However, when provided with defensive tools that highlight the negative explicit component of their attitudes toward the behaviors, respondents are able to dampen the increase in behavior caused by the act of prediction.
\end{abstract}

A sking consumers questions about their future behavior has long been known to result in biased responses and, more recently, has been found to lead to subsequent changes in the actual behavior being surveyed. For example, asking intention questions leads to an increase in the frequency of behavior that is desirable and to a decrease in the incidence of behavior that is undesirable (Morwitz, Johnson, and Schmittlein 1993; Sherman 1980). Similarly, asking questions can lead to changes in consumption patterns, such that customers who complete satisfaction surveys subsequently purchase more and are more loyal (Dholakia and Morwitz 2002). Furthermore, simply notifying consumers in advance that they will be asked to evaluate their satisfaction with a product or service has been found to change the consumer's experience substantially (Ofir and Simonson 2001).

Various mechanisms have been proposed to explain the effect that asking questions has on behavior. For one, questions may increase the accessibility of attitudes toward the

*Gavan J. Fitzsimons is professor of marketing and psychology at the Fuqua School of Business, Duke University, Durham, NC 27708 (gavan@ duke.edu). Joseph C. Nunes is associate professor of marketing at the Marshall School of Business, University of Southern California, Accounting 304, Los Angeles, CA 90089-0443 (jnunes@marshall.usc.edu). Patti Williams is associate professor of marketing at the Wharton School, University of Pennsylvania, 700 Jon M. Huntsman Hall, 3730 Walnut Street, Philadelphia, PA 19104-6340 (pattiw@wharton.upenn.edu). This research was supported in part by grant 1 P20 DA017589 from the National Institute on Drug Abuse, awarded to the first author through the Duke University Transdisciplinary Prevention Research Center. The authors contributed equally to this research. The order of authorship is alphabetical.

John Deighton served as editor and Stephen Nowlis served as associate editor for this article.

Electronically published April 5, 2007 target behavior (Fitzsimons and Morwitz 1996; Morwitz and Fitzsimons 2004). Second, questions may increase the perceptual fluency of the target (Janiszewski and Chandon 2004), making perceptions at the time of judgment easier. Third, asking questions reminds people of the inconsistency between what they want to do and what society says they should do, leading them to behave in concert with social norms in order to avoid cognitive dissonance (Spangenberg et al. 2003). And finally, the "positivity effect" proposes that surveys themselves provide a useful source of information regarding the questioner, leading consumers to generate positive inferences (Dholakia, Morwitz, and Westbrook 2005). All of these explanations share a common thread-a question about future behavior leads to a change in actual behavior consistent with the respondent's opinion of the behavior. That is, questions about behaviors that respondents view positively will lead to an increase in this behavior, while questions about behaviors viewed negatively will lead to a decrease.

But what if a respondent holds both positive and negative attitudes toward a single behavior? Research on attitude formation and application has increasingly recognized that attitudes can comprise separate negative and positive components (Cacioppo and Berntson 1994), which can result in attitude ambivalence (Thompson, Zanna, and Griffin 1995). In the present research we focus on vice behaviors, those for which consumers maintain a positive implicit attitude and negative explicit attitude. We demonstrate that asking consumers to report their expectations regarding how often they will perform a vice behavior increases the incidence of these behaviors. We propose that the question itself makes the implicit positive attitude more accessible and, thus, that reporting expectations appears to serve as a liberating in- 
fluence allowing consumers to indulge in their desires more frequently than they would have otherwise. We argue that the effect will be more pronounced for those chronically low in self-control, for whom questioning their behavior also serves to erode confidence in their ability to abide by their explicit attitudes. Finally, we show how the effect can be diminished or even negated through actions that highlight the negative explicit attitude toward the behavior.

The rest of this article proceeds as follows. First, we briefly review the relevant research on attitude ambivalence, selfcontrol, and self-regulation in situations involving conflicting attitudes. Next, we present the results of four studies. In study 1 , we document how asking a question regarding the expected frequency of a vice behavior increases the incidence of the behavior. Actual college students asked how often they intend to miss class exhibit higher absentee rates, as tracked by the instructor, than those not asked. In study 2, utilizing the intention question from study 1 , we show how questions pertaining to behaviors about which people hold negative explicit and positive implicit attitudes make the positive implicit attitude more accessible. In study 3, utilizing intention questions about a variety of vice behaviors, we explore how making predictions can erode the confidence of those low in selfcontrol. Finally, in study 4, we test two important potential moderators of the effect: formulating implementation intentions and precommitting to a self-reward. We conclude by discussing the implications for researchers and public policy makers interested in vice behaviors.

\section{ASKING QUESTIONS ABOUT VICE BEHAVIORS}

The vast majority of research examining the effect of asking questions on actual behavior has focused on behaviors toward which respondents are assumed to hold a relatively simple, straightforward attitude, either positive or negative. However, researchers are increasingly aware that individuals often hold conflicting or ambivalent attitudes (e.g., Cacioppo and Berntson 1994). A variety of underlying mechanisms have been proposed to lead to such ambivalence. For example, under the tripartite view-which posits that attitudes consist of affective, cognitive, and behavioral components (Breckler 1984)_individuals might feel intercomponent conflict between their emotions, or what their hearts tell them, and their beliefs, or what their minds say (Shiv and Fedorikhin 1999). Alternatively, they may experience intracomponent inconsistency when they hold, for example, conflicting cognitions about the same object (Thompson et al. 1995). In addition, consumers might experience interpersonal attitude ambivalence when their evaluations conflict with those of positively valued others (Priester and Petty 2001).

Attitudinal conflict can occur consciously, such that consumers are aware of the inconsistency, and it can occur outside of their awareness, or nonconsciously. Devine (1989) proposes that attitudes are often formed in a twostage process. During the first stage, initial responses to certain objects are culturally defined and relatively automatic or implicit (i.e., occurring outside of conscious awareness). In a second stage, given motivation, individuals may retrieve or consciously form an explicit evaluation that may be in concert or in conflict with the implicit attitude. Similarly, Wilson, Lindsey, and Schooler (2000) present a theory of "dual" attitudes. In this model, people often have long-standing (implicit) attitudes, such as habitual responses that are easy to retrieve (see also Greenwald and Banaji 1995). Simultaneously, more recently constructed conscious evaluations (explicit attitudes) often develop, which are context dependent, vary greatly in accessibility, and require capacity and motivation to retrieve. The implicit and explicit attitudes coexist and may often be in conflict with one another; given the nonconscious nature of the implicit attitude, however, consumers may be unaware of the conflict and thus may experience few subjective feelings of distress.

Vice behaviors such as smoking, drinking, and using drugs are likely to be activities about which consumers hold conflicting attitudes. While smokers may on one level wish that they did not smoke, on another level they clearly maintain a desire to engage in the behavior. These "guilty pleasures" often lead to immediate positive outcomes but bring substantial negative consequences in the long term, resulting in ambivalent attitudes (Giner-Sorolla 2001). What will be the impact of asking questions about future behavior when consumers hold both positive and negative attitudes toward the target behavior?

Several streams of research suggest that the positive attitude toward engaging in the risky behavior may well win out and guide actions among respondents who truly hold both positive and negative attitudes. In their work on the conflict between affective and cognitive components of decision making, Shiv and Fedorikhin (1999) demonstrated that in situations of affective and cognitive attitudinal conflict, consumers are more likely to rely on the affective component, unless they are motivated and possess substantial capacity to engage in self-controlling cognitive activity. A similar prediction arises from research on dual attitudes (e.g., Wilson et al. 2000), which has shown that implicit attitudes are more likely to guide actions when the behavior is more impulsively based. In the case of vice behaviors, many individuals may hold both an explicit, negative attitude toward the behavior (e.g., smoking is bad) and an implicit (or nonconscious) positive attitude (e.g., I like smoking at parties).

There is evidence that the underlying processes related to general question-behavior effects (i.e., the effect of asking intention questions on subsequent behavior) influence more automatic or implicit processes rather than more thoughtful and deliberative activity. Using process dissociation procedures (Jacoby 1991) to isolate the automatic versus effortful components of the question-behavior effect, Fitzsimons and Williams (2000) found the effect of asking intentions on subsequent behavior to be primarily an automatic process. To override the effect, respondents would need to invoke relevant effortful processing. However, be- 
cause intention questions are perceived by consumers as benign queries that are incapable of influencing behavior (Williams, Fitzsimons, and Block 2004), these questions fly "under the radar" of defensive processing. In other words, the effortful defensive processing aroused when a respondent encounters something commonly known to have persuasive intent, such as advertising or a sales pitch (Friestad and Wright 1994), is not activated when respondents encounter intention questions.

Further, research on both affective and cognitive attitude conflict and on implicit and explicit attitude conflict suggests that individuals asked a question about future vice behavior will be likely to report relatively negative attitudes toward the behavior (Shiv and Fedorikhin 1999; Wilson et al. 2000). These negative attitudes are likely to be more cognitive and are, by definition, explicit in nature. However, each of these research streams also suggests that the act of answering the question will activate a conflicting implicit, affectively based positive attitude that is in favor of engaging in the vice behavior. When respondents find themselves in situations in which highly deliberative, effortful self-regulatory behavior is not likely, and they are asked intention questions, we believe that their implicit attitudes in favor of engaging in the vice behavior are likely to become more accessible and thus guide their actions. Consequently, we expect to witness an increase in the actual vice behavior in response to intention questions, despite negative explicit attitudes toward the behavior.

\section{STUDY 1-HITTING THE SNOOZE BUTTON}

In our first experiment, we set out to demonstrate the effect of answering an intention question about a vice behavior on subsequent behavior in the real world. To do so, we selected an environment in which respondents had attitudes both in favor of and against the targeted vice behavior. To avoid any interference that measuring attitude ambivalence might have on behavior, this conflict was not addressed in study 1 but was validated in study 2 . We chose a vice behavior that carried very real, long-term negative repercussions should respondents decide to engage in it. Further, we did not rely on self-reports regarding the frequency of undesirable behavior but, rather, directly measured the actual frequency ourselves.

\section{Method}

Participants. Participants in this study were 81 undergraduate students enrolled in a marketing course at the University of Southern California. At the introduction of the course, all of the participants answered a series of questions as part of the course proceedings.

Design and Procedure. On the first day of class, participants were provided a student questionnaire along with the course syllabus and other materials. The questionnaire asked students to report which other marketing courses they had taken as well as a number of other questions concerning their curriculum, plans for after graduation, and miscellaneous facts about themselves. Included in half of the surveys, which were distributed randomly across two sections of the class, was the focal question, which involved predicting the number of classes students expected to miss during the semester (approximately 16 weeks). Half of the students $(N=41)$ were asked to predict their absences, while the remainder of the class members $(N=40)$ served as a control group and were never asked any questions about their attendance. At the beginning of the semester it was made clear to the participants that the class participation component of their grade $(10 \%)$ was based in part on students being present and prepared at every class. Throughout the semester the number of classes each participant actually missed was monitored and recorded. We predicted that those who answered a question about their future class attendance would miss more classes, on average, than their counterparts who did not make such a prediction.

\section{Results}

Participants who were asked to predict how many classes they would miss reported that they anticipated missing 2.98 classes, on average, with a range from one to five. Participants who did not make a prediction actually missed an average of 2.95 classes, while those who had responded to the question about their future behavior missed an average of 3.78 classes, a significantly greater number $(t(79)=$ $2.22, p<.05)$. Despite random assignment within each class, to rule out any effects resulting from class session (one was an early morning section, while the other met at noon), we ran a separate ANOVA in which the number of classes missed was compared across class sections. There were no significant differences $(F(1,79)<1, p=.97)$.

\section{Discussion}

Despite very real negative repercussions, respondents to a question about their future class attendance engaged in the negative behavior (missing class) at a significantly greater rate than those not asked to predict their absences. Most respondents likely held conflicting attitudes about missing class: missing class was bad and had real consequences in terms of learning and grades earned. And yet, missing class was good, as sleeping late and engaging in leisure activities could be substituted for class. Study 1 provides empirical evidence that questions about future behavior can liberate people to engage more readily in a vice behavior.

In study 1 , however, we did not directly measure participants' explicit or implicit attitudes toward skipping class, as the measurement of their attitudes would have been confounded with asking them to estimate how many classes they would skip. Therefore, in the next study, we confirmed that members of the target population held conflicting attitudes toward skipping class and that asking intentions questions increased the accessibility of the positive, implicit component of conflicted attitudes. 


\section{STUDY 2-NOW THAT YOU ASK, SKIPPING CLASS FEELS GOOD}

In study 2 we asked respondents to report their attitude (explicit) toward skipping class, while measuring their implicit attitude toward the same behavior. A priori, we predicted that participants would express a negative explicit attitude toward absenteeism but would reveal more positive implicit attitudes. In addition, we assessed the impact of an intention question on the accessibility of the implicit positive attitude toward skipping class. We predicted that participants who had been asked their intentions about skipping class would have more accessible implicit positive attitudes toward the behavior than respondents whose intentions were not questioned.

\section{Method}

Participants. Respondents were 29 undergraduate students at Duke University, drawn from a population similar to those in study 1, who took part in the study in exchange for partial course credit.

Design and Procedure. Experiment 2 was a singlefactor, between-subjects design in which one-half of the participants were asked to estimate how often they would skip class during the subsequent week ("predict" condition), while the remaining half were asked to estimate how often they would engage in an entirely unrelated behavior ("control" condition). Participants seated at a computer were told that they would be asked to answer a series of questions on screen about commonly encountered consumer products and student situations. They then answered three filler questions. The first addressed how often they expected to visit a grocery store; the second, how often they expected to exercise; and the third, how often they thought they would visit a corner store or convenience store during the coming week. Next, participants in the predict condition were asked: "How many times will you skip class in the coming week?" Participants in the control condition were asked: "How many times will you floss your teeth in the coming week?"

All participants then completed a response time task designed to measure their implicit attitude toward skipping class. They were told: "In this next phase of today's study, we would like you to respond to a series of words presented to you on the screen. As each word appears on the screen, please press the J key if the word (e.g. friend) is positive, and the F key if the word (e.g. enemy) is negative. Please position your fingers now over the $\mathrm{F}$ and $\mathrm{J}$ keys, and hit the appropriate keys as accurately and quickly as possible."

Participants were then presented with a list of 10 words or short phrases (e.g., "milk," "studying"). The eighth item presented was the target behavior, "skipping class." Finally, participants answered a series of filler questions as well as an explicit attitude question about skipping class. They were told: "In this final phase of the study we would like your opinion of some common products and student issues. On a scale of $1-7$ (where $1=$ extremely negative and $7=$ extremely positive), please indicate your attitude toward these products and issues." Participants then answered the following three questions: How do you feel about shopping at grocery stores? How do you feel about studying? How do you feel about skipping class?

\section{Results}

Across conditions, the average explicit attitude toward skipping class was 1.97 (with $1=$ extremely negative and 7 = extremely positive). The difference between the prediction and control conditions on this measure was not statistically significant. Those in the prediction condition reported an explicit attitude of 2.0, whereas those in the control condition reported an explicit attitude of $1.93(F(1,27)=$ $.07, p=.80)$. The implicit attitude was determined by participants' instantaneous responses-whether or not they pressed the "good" or "bad" key during the response time task (Fazio 1990). Across conditions, 86.2\% of respondents (25 out of 29) pressed the good key when asked to assess as quickly as possible whether skipping class was good or bad. Again the difference across conditions on this measure was not significant statistically. Ninety-three percent of those in the predict condition (13 of 14) pressed the good key with respect to skipping class, compared with $80 \%$ (12 of $15)$ of those in the control condition $\left(\chi^{2}(N=29)=\right.$ $1.01, p=.31)$. Thus, while participants expressed strong negative explicit attitudes toward skipping class, they held positive implicit attitudes consistent with our expectations involving attitude ambivalence. Being asked to make a prediction about the behavior did not influence the underlying attitudes or the amount of implicit or explicit conflict toward the behavior.

While there were no differences in attitudes based on whether respondents were asked to predict their behavior, there were significant differences in the accessibility of the positive implicit attitude toward skipping class, indicated by significant differences in response latencies. Several steps were taken to analyze the response times accurately, consistent with methods outlined in Bargh and Chartrand (2000). Participants' responses to the first three (of 10) items were deleted, as these trials provided an opportunity for the participants to become familiar with the task. In addition, we used the average response time for items 4-7 and items 9-10 (item 8 was the target item: skipping class) as a covariate $(F(1,26)=2.71, p=.11)$ to account for individual differences in overall speed of response. There was a significant effect of asking respondents to estimate how many times they would skip class in the coming week on the speed with which they indicated that the behavior was good or bad (mean response $=558$ milliseconds) versus the control group (mean response $=780$ milliseconds; $F(1,26)=$ $5.21, p=.03)$.

\section{Discussion}

In study 1 we found that asking respondents to predict the number of classes they would skip liberated them to 
engage in the vice behavior more frequently. We predicted that this effect resulted from ambivalence in respondents' explicit and implicit attitudes. More specifically, we expected participants held negative explicit attitudes but positive implicit attitudes toward skipping class. Study 2 provided evidence of this conflict. The combination of results from studies 1 and 2 was consistent with our conjecture that asking an intention question has a nonconscious impact on respondents, making their implicit positive attitude toward the vice behavior more accessible. This implicit positive attitude could then predispose them to skip more classes than those respondents, whose implicit attitudes were not similarly highlighted, in a control condition.

\section{STUDY 3-I THINK I CAN, I THINK I CAN}

In studies 1 and 2, we observed that respondents asked how many classes they expected to miss went on to miss more classes than those not asked to report their expectations. Further, we found that asking an intention question made the underlying, positive implicit attitude toward an ostensibly negative behavior more accessible. Thus, the act of responding to an intention question may increase the underlying conflict between explicit and implicit attitudes toward the behavior. In study 3, we attempted to provide further evidence that responding to an intention question about a vice behavior leads to increased conflict between implicit and explicit positive attitudes in two ways. First, we examined an additional dependent variable that should be sensitive to an underlying implicit-explicit conflict: respondents' self-confidence in their ability to avoid the vice behavior. Second, we also examined a potential moderator of the effect of asking about vice behaviors - the degree to which individuals may be differentially vulnerable to their implicit positive attitudes and, thus, potentially more at risk when responding to a question about a vice behavior.

We collected a second dependent variable in addition to actual behavior, a subjective assessment of respondents' selfconfidence in their ability to avoid the vice behavior about which we asked. Respondents were asked to report how confident they were in their ability to follow their negative, explicit attitude toward the vice behavior. We predicted that participants who responded to a question about their future behavior would feel less confident in their ability to selfregulate successfully, as a result of their increased implicit versus explicit attitudinal conflict.

We also attempted to provide further evidence that responding to an intention question leads to increased implicit, positive attitudes toward a vice behavior by examining a factor that should moderate the degree to which a positive implicit attitude would guide respondent confidence and behavior. We examined the degree to which individuals might be differentially vulnerable to their implicit positive attitudes and, thus, potentially more at risk when responding to a question about a vice behavior. We expected that those who are more susceptible to giving in to their implicit desires may be more profoundly affected by the influence of intention questions on subsequent behaviors. To assess this, we had respondents provide responses to a scale measuring selfcontrol. We expected that participants who are low in selfcontrol are more likely to have confidence in their selfregulatory abilities shaken by a seemingly innocuous intention question, as their implicit attitudes are likely to play a greater role in their decision making.

Finally, in studies 1 and 2, we presumed that attractive alternative activities (to attending class) existed, which created the conflicting attitude that led participants to miss more classes after responding to a question about their future behavior. In study 3, we deliberately presented respondents with a behavioral opportunity that directly taps into an indulgent attitude. This indulgent attitude is in direct conflict with explicitly reported attitudes stating that engaging in the vice behavior is negative.

\section{Method}

Participants. Participants were 96 undergraduate students at the University of Southern California who took part in exchange for partial course credit.

Design and Procedure. Experiment 3 was a single factor, between-subjects design in which half of the participants provided an estimate of how often they might be distracted from studying by an alternative activity (predict condition) and half of the participants provided no such estimate (control condition). The wording of the question about future behavior was as follows: "Please tell us how many times in the following week ( 7 days) you expect to engage in an activity that distracts you from studying when you were previously planning to study?" Both predict and control condition participants then assessed how confident they were of never engaging in an alternative activity instead of studying during the coming week (or completely avoiding tempting alternatives over the coming week): "What is the likelihood of you never engaging in an alternative activity and, in fact, studying every time you were planning to study? Please answer by indicating your degree of confidence in percentage terms. I am \% (between $0 \%$ and 100\%) sure that I would study every time I had planned to study." Next, all participants completed a 13-item self-control scale designed to assess individual differences in the ability to self-control or self-regulate (the Brief Self-Control Scale; see Tangney, Baumeister, and Boone [2004]; sample items include "I wish I had more self discipline" and "I am able to work effectively toward long term goals"). Finally, all participants completed a behavioral measure designed to assess how successful they would be at avoiding temptations that might interfere with their studying in the coming week. They were told that "Universal Studios and Village Roadshow Productions may raffle off a bundle of tickets to four separate new movie screenings scheduled next semester. To qualify, you must attend at least four movies in a single week and be willing to fill out a questionnaire after each. If you are interested in participating, please provide your email address." Providing an e-mail address for the movie 
screenings was taken as a failure in self-control to avoid temptations that might interfere with studying behavior.

\section{Results}

As in studies 1 and 2, asking about respondents' intentions to engage in the vice behavior led to increases in their actual rates of the behavior. Those who responded to questions about their future behavior were more likely to change their subsequent actions by providing an e-mail address (encouraging an opportunity to be further distracted) by a margin of $76.6 \%$ versus $53.1 \%$ for those in the control condition $\left(\chi^{2}(N=96)=5.80, p<.05\right)$.

As expected, participants asked to "predict" their behavior were also significantly less confident in their ability to achieve perfection, as defined by "never engaging in an alternative activity" when they were planning to study. The likelihood of never being distracted for those who were asked to estimate how many times they expected to be distracted while attempting to study was $44.8 \%$ versus $62.9 \%$ for those who did not make an estimate $(F(1,95)=9.65$, $p<.01)$. Those who made predictions with regard to failings reported being less confident regarding their potential for success. This result provides convergent evidence that asking participants to predict their behavior is likely to have increased the conflict between implicit and explicit attitudes, as the increased conflict is manifest through a decreased confidence in their ability to avoid the vice.

An examination of the data with respect to individual differences in self-control provides further support for the conjecture that responding to a question activates positive attitudes toward the vice behavior and increases conflict with the negative attitude but does so to a greater extent for those with limited self-control. We performed a median split based on the self-control scale, dividing respondents into low and high self-controllers. Subsequently, we ran a 2 (estimate: predict/control, between) $\times 2$ (self-control: low vs. high, measured) between-subjects ANOVA with confidence in one's ability perfectly to avoid tempting alternatives as the dependent variable. Due to three incomplete responses to the self-control scale, this analysis is based on 93 observations. We observed both a main effect for estimate, as reported above, and a main effect for self-control, such that participants who were high self-controllers were significantly more confident $(60.8 \%)$ than those who were low self-controllers $(45.9 \%, F(1,88)=6.45, p<.05)$, as expected.

More interesting and consistent with our conjecture that making an estimate may increase conflict and weaken beliefs for those who are susceptible, we observed a significant two-way interaction between estimate and self-control $(F(1,88)=4.43, p<.05)$, such that the effects were present for respondents with low self-control, but not for those high in self-control. Among low self-controllers, those in the predict condition were significantly less confident $(30.5 \%)$ than those in the control condition $(62.9 \%, F(1,88)=11.83$, $p<.01)$. For high self-controllers, the effect of making an estimate was much weaker and resulted in a much smaller decrease in confidence. High self-controllers in the predict condition were directionally, but not significantly, less confident $(55.5 \%)$ than control participants $(65.5 \%, F(1,88)=$ $1.53, p=.22)$.

A similar pattern of results was obtained examining the interaction between high or low self-control and also an estimate or control on whether participants provided an email address or not, although neither the interaction nor the planned contrasts were significant. The lack of a significant interaction with self-control on the behavioral measure may have been an unintended by-product of the nature of the dependent variable. As tickets to movie screenings would be quite valuable in the area the study took place, some participants with very negative attitudes about the vice behavior (attending films instead of studying) may have indicated they would like them so that they could sell or give them to friends. As a function of this, the confidence measure (which would not be vulnerable to this weakness) appears to have been more sensitive in this situation.

\section{Discussion}

As in study 1, we found that asking questions about future vice behaviors changed the propensity to engage in the behavior subsequently. In study 3, we also demonstrated that responding to a question about future vice behavior weakens a respondent's confidence in the ability to avoid the vice behavior, providing convergent support to the idea that the act of answering a question about such behaviors leads to increased conflict between implicit and explicit attitudes. This lack of confidence is accompanied by an act that, while perhaps not directly surrendering to temptation, as in study 1 , certainly is likely to cause further conflict with the goals of studying and avoiding distraction. Accepting invitations to distracting activities reveals a lack of self-control, and, perhaps ironically, those perhaps most in danger of failing to study as planned (lowest in confidence) were the most eager to welcome temptation.

It appears that questions about future vice behaviors heighten the accessibility of a positive implicit attitude toward the behavior that the respondent had hoped to avoid (activities interfering with studying) and that conflicts with explicit or cognitively based attitudes (I must study and studying is good). But what if these respondents were equipped with a plan to support and perhaps heighten the accessibility of their negative attitude toward the vice behavior? Might they then be better able to forgo temptation? These specific questions were addressed in study 4 .

\section{STUDY 4-JUST ONE MORE DRINK?}

In study 4 we extended the previous results to two additional vice behaviors as well as examined potential mechanisms that might be used to defend against undesired increases in vice behavior resulting from the act of making predictions. More specifically, we examined two mechanisms that have been suggested for increasing the motivation or ability to avoid temptations: (i) precommitting to a selfreward for success in avoiding the vice behavior and (ii) 
forming implementation intentions to help avoid the vice behavior. As such, we expected these two mechanisms to moderate the previously observed effects, as they provide a counterweight to the nonconscious heightening of the positive implicit attitudes that comes after a response to an intention question.

Gollwitzer $(1993,1999)$ has proposed that implementation intentions, as distinct from goal intentions, both in terms of structure and content, improve individuals' likelihood of achieving desired ends. A goal intention is of the form, "I plan to achieve goal x," whereas an implementation intentions has the form, "If I encounter situation y, I will perform the goal-directed action x." Whereas goals are broad and not necessarily context specific, implementation intentions are explicitly context specific and much more detailed and action oriented. They provide an actionable plan for achieving a goal rather than just forming the goal itself. As such, instructing respondents to generate an implementation intention after they have made an estimate of how often they will engage in a vice behavior should equip the respondents with an increased ability to succeed in their overriding avoidance intention and potentially override the vice-increasing impact of forming an estimate. Similarly, we anticipated that having respondents commit to a self-reward if they were successful should lead to a dampened effect for forming an estimate. While implementation intentions likely operate by increasing both avoidance motivation and ability, a self-reward should affect only the motivation to avoid the vice behavior.

\section{Method}

Participants. Participants were 135 undergraduate students at the University of Pennsylvania, who took part in the study in exchange for partial class credit. The experiment took place in two class sessions held 1 week apart. One hundred and twenty-one participants completed both sessions, and their responses are used in this analysis.

Design and Procedure. In this experiment, two behaviors were the potential targets of a question about future vice behavior. The first behavior was going out drinking (defined as consuming more than two alcoholic beverages in a day or night). The second behavior was watching television instead of studying (defined as watching at least 15 minutes of television at a time when the participant should be studying or doing class-related work). Participants were asked to estimate either how many times they would go out drinking or how many times they would watch television instead of studying:

\section{Drinking estimate:}

Please estimate how many times you will go out drinking in the next week (i.e. how many times over the next seven days you will consume more than two alcoholic beverages in a day or night).

I will go out drinking times.
$T V$ instead of studying estimate:

Please estimate how many times in the next week you will watch television when you should be studying (i.e. how many times over the next seven days you will watch at least 15 minutes of television at a time you should be studying or doing class related work).

I will watch television instead of studying times.

In addition, two additional manipulations were run for each behavior by adding either an implementation intention condition or a self-reward condition. Thus, six different conditions were run. For drinking behavior, the conditions were prediction only, prediction plus implementation intentions, and prediction plus self-reward. For watching television instead of studying, the conditions were prediction only, prediction plus implementation intentions, and prediction plus self-reward. Participants were assured that their responses would remain entirely confidential. Examples of both supplementary instructions are given for the drinking prediction conditions:

\section{Implementation intentions (drinking):}

In order to achieve their goals people execute behaviors that can be described along three dimensions: One refers to the point in time, the second to the place, and the third to the type of action that is linked to the situational context specified by that time and place.

With respect to your drinking behavior over the next week, please describe specific actions you would take in different contexts to achieve your goal. An example of this form of statement might be: "When I encounter situation $\mathrm{x}$, I will perform y to be sure I achieve my drinking related goal." Please make at least one, and as many of these statements as you might like.

\section{Self-reward (drinking):}

In order to achieve their goals people often reward themselves afterwards. With respect to your drinking behavior over the next week, please describe a reward you might give yourself for meeting your drinking related goal.

One week after the participants answered the question about their future drinking or television-watching behavior, they answered an unexpected follow-up questionnaire that asked them to report both how many times they had consumed more than two drinks in a sitting in the previous week and how many times they had watched television instead of studying over the previous week. Again, participants were assured of the confidentiality of their responses to the survey questions. By collecting information on both behaviors for all participants, it allowed respondents initially asked to estimate their future drinking to serve as a control group for the group questioned about watching television instead of studying. Similarly, those respondents initially asked to estimate their television viewing served as a control group for those asked about their drinking behavior. 


\section{Results}

Fourteen of the original 135 participants did not return for the second session, held 1 week after the first, resulting in responses from 121 participants that were used for subsequent analyses. As we predicted, and consistent with previous results, asking participants to make a prediction about the likelihood of participating in vice behaviors for which they likely hold positive implicit attitudes led to increases in their actual behavior. Making a prediction led to an increase in drinking during the subsequent week for the drinking prediction-only group (3.22 times) versus the groups in three control conditions not asked to make a drinking estimate $(1.23$ times, $F(1,115)=29.03, p<.001)$. Similarly, making a prediction about watching television instead of studying led to an increase in this behavior for participants in the watching television prediction-only condition (3.93 times) versus participants in the three conditions where they were not asked to make an estimate of watching television instead of studying (2.66 times, $F(1,115)=6.19, p<.05)$.

Both manipulations that were designed to focus respondents to avoid engaging in the undesirable behavior met with success. Among those who made estimates of their future television watching instead of studying behavior, both forming implementation intentions and committing to a selfreward served to counteract the increase in television watching caused by making a prediction. Participants who formed implementation intentions in addition to estimating their behavior watched significantly less television in lieu of studying (1.90 times) than did those in the prediction-only condition $(3.93$ times, $F(1,115)=7.49, p<.01)$ and, in fact, watched no more television (vs. studying) than did those in the control group not asked to make a prediction (2.66 times, $F(1,115)=1.49, p=.22$ ). Participants who formed selfrewards in addition to estimating their behavior watched significantly less television instead of studying (1.26 times) than did those in the prediction-only condition (3.93 times, $F(1,115)=19.59, p<.001)$ and significantly less than those in the control group $(2.66$ times, $F(1,115)=10.16$, $p<.01)$.

Results were similarly effective in negating the effect of predictions on drinking behavior. Both implementation intentions and self-rewards helped lower the incidence of drinking behavior in respondents relative to respondents in the prediction condition. Participants who formed implementation intentions in addition to estimating their drinking behavior engaged in significantly less drinking (1.71 times) than did those in the intention-only condition (3.22 times, $F(1,115)=12.20, p<.001)$ and were not statistically different from the control group's level of drinking (1.23 times, $F(1,115)=1.54, p=.22)$. Similarly, participants who committed to self-rewards in addition to estimating their drinking behavior engaged in significantly less drinking (1.45 times) than did those in the intention-only condition (3.22 times, $F(1,115)=15.87, p<.001)$ and, again, were not statistically different from those in the control group (1.23 times, $F(1,115)=0.32, p=.57)$. We also conducted a second analysis in which actual behavior regarding drink- ing and watching television was standardized, and a 3 (question form: prediction only, prediction plus implementation intentions, and prediction plus self-reward) $\times 2$ (behavior predicted: drinking or watching television) $\times 2$ (dependent variable: actual drinking or actual television watching) mixed ANOVA was run with question form and behavior predicted as between-subjects factors and with the dependent variable as a within-subjects factor. As expected, the threeway interaction was significant $(F(2,115)=8.46, p<$ .001 ), and the pattern of effects was identical to that presented above.

\section{Discussion}

In study 4 , we provided a means of defense to respondents, such that the act of predicting performance of a guilty pleasure would not lead to increases in the behavior. For two behaviors (drinking more than two alcoholic beverages in a sitting and watching television instead of studying) participants were asked a question about their behavior in the near future. As in the earlier studies, making a prediction served a liberating role. Alcohol consumption rose as a function of making a prediction (both the number of days alcohol was consumed and maximum consumed in a sitting), as did the number of times they watched television instead of studying (3.93 times vs. a control rate of $2.61, p<.01$ ). However, when respondents were given defensive tools that heightened their negative attitudes - that drinking and wasting time watching television are to be avoided-they were able to eliminate the increase in the behavior caused by the act of prediction. Both tools, implementation intentions (Brandstätter, Lengfelder, and Gollwitzer 2001) and a precommitted self-reward, as conscious, explicit strategies, likely increased the salience of the explicit desire to avoid the vice behavior and thus counteracted the nonconscious question-driven activation of the implicit desire to indulge.

Implementation intentions may provide respondents with a method for achieving their long-term goal, in line with their explicit attitudes. Yet, both implementation intentions and committing to a self-reward may also simultaneously activate and strengthen an overriding goal to engage in selfregulation and avoid the vice behavior if the presence of temptations automatically activates higher-order overriding goals (Fishbach, Friedman, and Kruglanski 2003). Consistent with Shah, Friedman, and Kruglanski (2002), the activation of overriding goals could have inhibited the activation of implicit positive attitudes toward the tempting stimuli that would violate the overriding or long-term goal.

\section{GENERAL DISCUSSION}

Existing mechanisms that explain the impact of asking questions on actual behavior predict that changes in behavior will mirror attitudes; positive attitudes will lead to an increase in the behavior, while negative attitudes will lead to a decrease in the behavior. The present research extends this work by examining how intention questions affect behaviors for which people have conflicting attitudes-more specifi- 
cally, vice behaviors. With many of the behaviors tested in previous research (e.g., voting), respondents hold consistent attitudes (voting is good, and I should vote). However, with vice behaviors, people often possess both negative explicit attitudes (I should not smoke marijuana) and positive implicit attitudes (doing drugs is enjoyable). We have documented how the act of responding to a seemingly innocuous question is likely to trigger desires to engage in the vice behavior by making positive implicit attitudes more accessible.

Presuming, consistent with the results of our study 2 , that asking a question activates implicit positive attitudes toward the vice behavior that in turn guide behavior, it is interesting to consider the duration over which this increased accessibility of implicit positive attitudes might endure. We have documented the impact of questions on vice behaviors over a range of time horizons between question and behavior varying from a few minutes (i.e., study 3 ) to a week (i.e., study 4) to an entire semester (i.e., study 1). Similarly, other research has found evidence of seemingly long-lasting effects of intention questions on behavior. For example, Morwitz and colleagues (1993) found the impact of intention questions on the purchase of automobiles and personal computers over a 6-month period.

While many semantic primes seem to increase accessibility for only short periods (e.g., 5 minutes; see Bargh et al. 2001), a number of potential mechanisms might convert a short-term increase in the accessibility of an attitude to a long-term effect on behavior. First, the short-term increase in attitude accessibility and subsequent behavioral outcome might make the respondent more attentive to future opportunities for the reactivation of the attitude or reengagement in the behavior. This increased likelihood of reactivation, essentially attitude rehearsal, may in turn further increase accessibility and the strength of the underlying implicit attitude. Thus, once the attitude has been highlighted, a cycle of reinforcing actions might occur to maintain that heightened accessibility over time. Second, some research has suggested that memory for intended future actions is unique in its ability to remain at a heightened level of activation for a sustained period of time, until the intended behavior has been fully accomplished (e.g., Marsh, Hicks, and Bink 1998). If asking a question about future behavior activates an intention to engage in such behaviors, this may account for the persistency of the activation. A third explanation may be that asking a question about a vice behavior does not simply increase the accessibility of the attitude but could lead to the formation or activation of an attitude-relevant goal. Goals have been shown to have much longer endurance than simple semantic activation and, in many cases, will persist in activation until satisfied (Bargh et al. 2001). While we did not isolate a single explanation in this work, future research exploring how activating implicit attitudes toward vice behaviors leads to enduring behavioral change would certainly be warranted.

The fact that asking questions about vice behaviors can increase actual vice behavior clearly poses a public policy dilemma for survey researchers interested in understanding vice behaviors so that they can discourage them. Fortunately, we also document two moderators of the effect that can prevent intention questions from exacerbating indulgences in vices: (a) having people consider how they might avoid the behavior and $(b)$ having people create a self-reward for sticking with their stated usage patterns. At issue, of course, is: "What is the most accurate gauge of behavior other than observing it firsthand?" While we raise many issues for those engaged in survey research, we cannot offer a solution to ensuring that expectations are consistent with subsequent behavior. We do, however, offer recommendations for limiting the potentially negative impact of the question on the behavior.

Previous research has suggested a number of ways in which attitudes can be in conflict, such as differences among implicit and explicit attitudes or between the affective and cognitive components of attitudes. In study 2 , we found that our respondents held conflicting implicit and explicit attitudes toward skipping class and that the act of answering an intention question heightened the impact of their implicit positive attitudes toward the behavior. In the subsequent studies, we presumed that our respondents held similarly conflicting attitudes regarding activities that distracted them from studying and from going out drinking. We did not, however, explicitly assess the basis of that conflict. Our results suggest that conflict among explicit and implicit attitudes is certainly amenable to influence by asking questions about vice behaviors. Given the nonconscious impact intentions questions have on behavior, consumers may be most susceptible to their influence when they possess implicit attitudes that conflict with their explicit attitudes. However, previous work (Shiv and Fedorikhin 1999) suggests that a similar effect may be observed even among conflicting explicit attitudes as well.

In addition, our findings suggest that when consumers hold conflicting attitudes about vice behaviors, responding to an intention question activates the positive component of the attitude toward that behavior. It is likely, however, that this will depend on the way in which the intention question is worded. In other words, the question might be framed in such a way that it could highlight either the positive or the negative component of the conflicted attitude (Thompson et al. 1995). In studies 1 and 4, we ask how likely respondents are to engage in the vice behavior, in effect framing the vice behavior as something that will be done and, thus, perhaps activating the underlying positive evaluations of it. Perhaps another way of framing the question (e.g., How likely are you to avoid the behavior?) might make the negative component of the attitude more accessible and thus be more likely to drive behavior.

\section{REFERENCES}

Bargh, John A. and Tanya L. Chartrand (2000), "The Mind in the Middle: A Practical Guide to Priming and Automaticity Research," in Handbook of Research Methods in Social and 
Personality Psychology, ed. Harry T. Reis and Charles M. Judd, New York: Cambridge University Press, 253-85.

Bargh, John A., Peter M. Gollwitzer, Annette Y. Lee-Chai, Kimberly Barndollar, and Roman Troetschel (2001), "The Automated Will: Nonconscious Activation and Pursuit of Behavioral Goals," Journal of Personality and Social Psychology, 81 (December), 1014-27.

Brandstätter, Veronika, Angelika Lengfelder, and Peter M. Gollwitzer (2001), "Implementation Intentions and Efficient Action Initiation," Journal of Personality and Social Psychology, 81 (November), 946-60.

Breckler, Steven J. (1984), "Empirical Validation of Affect, Behavior and Cognition as Distinct Components of Attitude," Journal of Personality and Social Psychology, 47 (December), 1191-1205.

Cacioppo, John T. and Gary G. Berntson (1994), "Relationship between Attitudes and Evaluative Space: A Critical Review with Emphasis on the Separability of Positive and Negative Substrates," Psychological Bulletin, 115 (May), 401-23.

Devine, Patricia G. (1989), "Stereotypes and Prejudice: Their Automatic and Controlled Components," Journal of Personality and Social Psychology, 56 (January), 5-18.

Dholakia, Utpal M. and Vicki G. Morwitz (2002), "The Scope and Persistence of Mere Measurement Effects: Evidence from a Field Study of Customer Satisfaction Measurement," Journal of Consumer Research, 29 (September), 159-67.

Dholakia, Utpal M., Vicki G. Morwitz, and Robert A. Westbrook (2005), "Survey Participation Effects on Customer Purchase Behavior: Evidence for a Positivity Effect of Firm-Sponsored Satisfaction Surveys," MSI Working Paper Series, Marketing Science Institute, Cambridge, MA.

Fazio, Russell H. (1990), "A Practical Guide to the Use of Response Latency in Social Psychological Research," in Research Methods in Personality and Social Psychology, ed. Clyde Hendrick and Margaret S. Clark, Thousand Oaks, CA: Sage, 74-97.

Fishbach, Ayelet, Ronald S. Friedman, and Arie W. Kruglanski (2003), "Leading Us Not into Temptation: Momentary Allurements Elicit Overriding Goal Activation," Journal of Personality and Social Psychology, 84 (February), 296-309.

Fitzsimons, Gavan J. and Vicki G. Morwitz (1996), "The Effect of Measuring Intent on Brand-Level Purchase Behavior," Journal of Consumer Research, 23 (June), 1-11.

Fitzsimons, Gavan J. and Patti Williams (2000), "Asking Questions Can Change Choice Behavior: Does It Do So Automatically or Effortfully?" Journal of Experimental Psychology: Applied, 6 (September), 195-206.

Friestad, Marian and Peter Wright (1994), "The Persuasion Knowledge Model: People Cope with Persuasion Attempts," Journal of Consumer Research, 21 (June), 1-31.

Giner-Sorolla, Roger (2001), "Guilty Pleasures and Grim Necessities: Affective Attitudes in Dilemmas of Self-Control," Journal of Personality and Social Psychology, 10 (February), 206-21.

Gollwitzer, Peter M. (1993), "Goal Achievement: The Role of Intentions," European Review of Social Psychology, 4, 141-85.

(1999), "Implementation Intentions: Strong Effects of Simple Plans," American Psychologist, 54 (July), 493-503.

Greenwald, Anthony G. and Mazarin R. Banaji (1995), "Implicit Social Cognition: Attitudes, Self-Esteem and Stereotypes,"
Journal of Personality and Social Psychology, 102 (January), 4-27.

Jacoby, Larry L. (1991), “A Process Dissociation Framework: Separating Automatic from Intentional Uses of Memory," Journal of Memory and Language, 30 (October), 513-41.

Janiszewski, Chris and Elise Chandon (2007), "Transfer Appropriate Processing, Response Fluency, and the Mere Measurement Effect," Journal of Marketing Research, forthcoming.

Marsh, Richard L., Jason L. Hicks, and Martin L. Bink (1998), "Activation of Completed, Uncompleted and Partially Completed Intentions," Journal of Experimental Psychology: Learning, Memory and Cognition, 24 (March), 350-61.

Morwitz, Vicki G. and Gavan J. Fitzsimons (2004), "The Mere Measurement Effect: Why Does Measuring Intentions Change Actual Behavior?" Journal of Consumer Psychology, 14 (1-2), 64-74.

Morwitz, Vicki G., Eric Johnson, and David Schmittlein (1993), "Does Measuring Intent Change Behavior?" Journal of Consumer Research, 20 (June), 46-61.

Ofir, Chezy and Itamar Simonson (2001), "In Search of Negative Customer Feedback: The Effect of Expecting to Evaluate on Satisfaction Evaluations," Journal of Marketing Research, 38 (May), 170-82.

Priester, Joseph R. and Richard E. Petty (2001), "Extending the Bases of Subjective Attitudinal Ambivalence: Interpersonal and Intrapersonal Antecedents of Evaluative Tension," Journal of Personality and Social Psychology, 80 (January), 19-34.

Shah, James Y., Ronald S. Friedman, and Arie W. Kruglanski (2002), "Forgetting All Else: On the Antecedents and Consequences of Goal Shielding," Journal of Personality and Social Psychology, 83 (December), 1261-80.

Sherman, Steven J. (1980), "On the Self-Erasing Nature of Errors of Prediction," Journal of Personality and Social Psychology 39 (August), 211-21.

Shiv, Baba and Alexander Fedorikhin (1999), "Heart and Mind in Conflict: The Interplay of Affect and Cognition in Consumer Decision Making," Journal of Consumer Research, 26 (December), 278-92.

Spangenberg, Eric R., David E. Sprott, Bianca Grohmann, and Ronn J. Smith (2003), "Mass-Communicated Prediction Requests: Practical Application and a Cognitive Dissonance Explanation for Self-Prophecy," Journal of Marketing, 67 (July), $47-62$.

Tangney, June P., Roy F. Baumeister, and Angie L. Boone (2004), "High Self-Control Predicts Good Adjustment, Less Pathology, Better Grades, and Interpersonal Success," Journal of Personality, 72 (April), 271-322.

Thompson, Megan M., Mark P. Zanna, and Dale W. Griffin (1995), "Let's Not Be Indifferent about (Attitudinal) Ambivalence," in Attitude Strength: Antecedents and Consequences, ed. Richard E. Petty and Jon A. Krosnick, Mahwah, NJ: Erlbaum, 361-86.

Williams, Patti, Gavan J. Fitzsimons, and Lauren G. Block (2004), "When Consumers Don't Recognize 'Benign' Intention Questions as Persuasion Attempts," Journal of Consumer Research, 31 (December), 540-50.

Wilson, Timothy D., Samuel Lindsey, and Tonya Y. Schooler (2000), "A Model of Dual Attitudes," Psychological Review, 107 (January), 101-26. 